\title{
WestVirginiaUniversity
}

THE RESEARCH REPOSITORY @ WVU

Graduate Theses, Dissertations, and Problem Reports

2013

\section{The Influence of Memory Enhancement Techniques on Source Monitoring}

Ria M. Travers

West Virginia University

Follow this and additional works at: https://researchrepository.wvu.edu/etd

\section{Recommended Citation}

Travers, Ria M., "The Influence of Memory Enhancement Techniques on Source Monitoring" (2013). Graduate Theses, Dissertations, and Problem Reports. 5008.

https://researchrepository.wvu.edu/etd/5008

This Thesis is protected by copyright and/or related rights. It has been brought to you by the The Research Repository @ WVU with permission from the rights-holder(s). You are free to use this Thesis in any way that is permitted by the copyright and related rights legislation that applies to your use. For other uses you must obtain permission from the rights-holder(s) directly, unless additional rights are indicated by a Creative Commons license in the record and/ or on the work itself. This Thesis has been accepted for inclusion in WVU Graduate Theses, Dissertations, and Problem Reports collection by an authorized administrator of The Research Repository @ WVU. For more information, please contact researchrepository@mail.wvu.edu. 


\title{
The Influence of Memory Enhancement Techniques on Source Monitoring
}

Ria M. Travers, B.S.

\author{
Thesis submitted to the \\ Eberly College of Arts and Sciences \\ at West Virginia University \\ in partial fulfillment of the requirements \\ for the degree of \\ Master of Science \\ in \\ Psychology
}
Elisa Krackow, Ph.D., Chair
Julie Patrick, Ph.D.
Constance Toffle, Ph.D.
Department of Psychology
Morgantown, West Virginia
2012

Keywords: Source Monitoring; Focused Meditation; Motivational Instructions Copyright 2012 Ria M. Travers 


\begin{abstract}
The Influence of Memory Enhancement Techniques on Source Monitoring
\end{abstract}

Ria M. Travers

An important aspect of accurate eyewitness testimony is not only being able to recall the details of an event, but being able to trace that memory back to its source or origin (Johnson, Hashtroudi, \& Lindsay, 1993). The current study examined the use of two memory enhancement interventions to improve the accuracy of source memory, or the correct attribution of a memory to its origin, and free recall. The first intervention, motivational instructions, informed participants that they are capable of recalling an event if they try their best. The second intervention, focused meditation, used a breathing exercise to focus individuals' attention while they recalled the to-be-remembered stimuli. The study compared the efficacy of these two interventions to one another and a control condition in which participants completed the source monitoring test and free recall task without receiving a memory enhancement intervention.

Fifty-nine undergraduate college student participants viewed a video of an event and then answered written questions. Two days later, participants either received a memory enhancement technique or no technique. Following this, they received a source monitoring test during which participants listened to statements and were asked to identify the source of the statement. Next, they free recalled all details they remembered about the event. The number of correct ideas recalled and the number of incorrect ideas were calculated and statistically compared across conditions. The number of correct responses to the source monitoring questions was also compared across conditions.

The two memory enhancement techniques were not found to increase source monitoring accuracy or accurate free recall compared to the no-intervention control condition. These results suggest that focused meditation and motivational instructions may not be effective in increasing accurate source memory on the source monitoring task that was used. The result that these techniques did not increase free recall is unexpected, and may be due to procedural ideas of the study design. 


\section{Table of Contents}

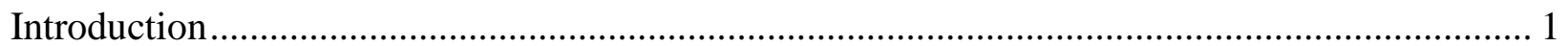

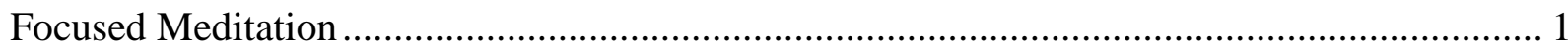

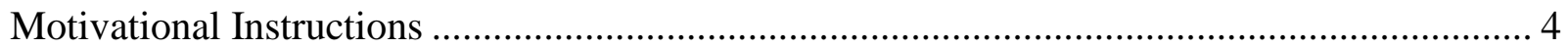

Other Well-Researched Memory Enhancement Techniques ................................................ 6

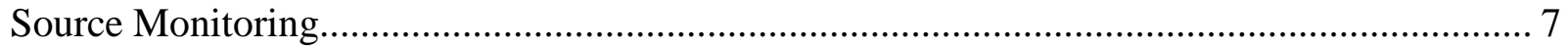

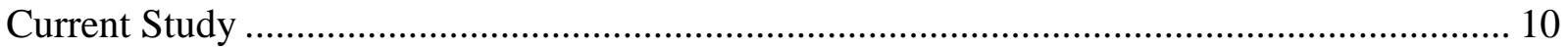

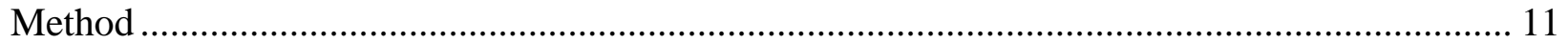

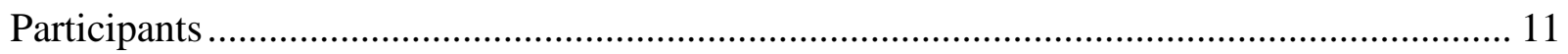

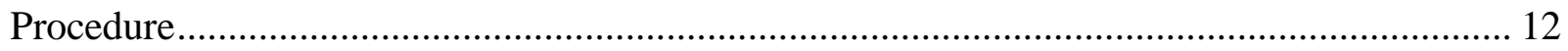

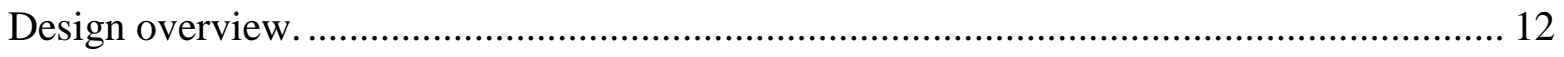

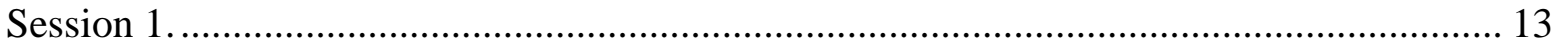

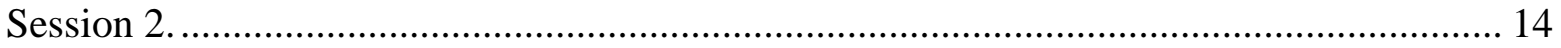

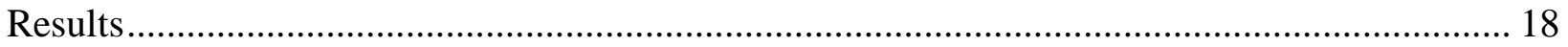

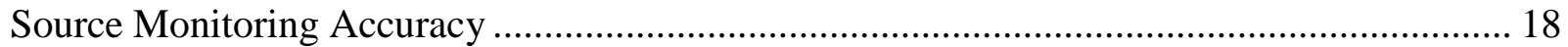

Free Recall Memory Accuracy: Correct and Incorrect Recall ........................................... 19

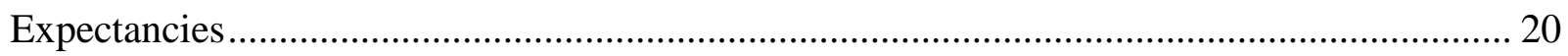

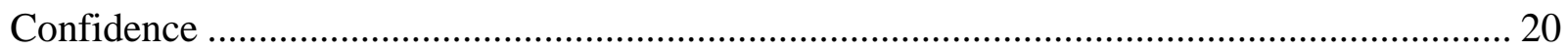

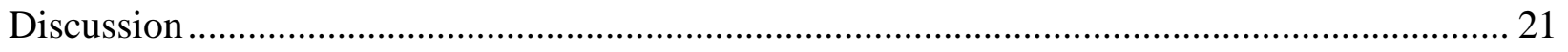

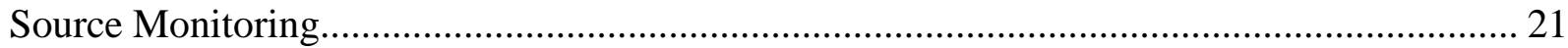

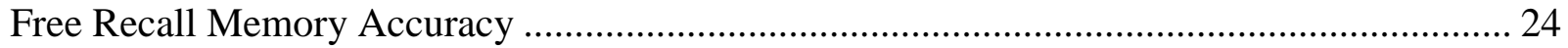

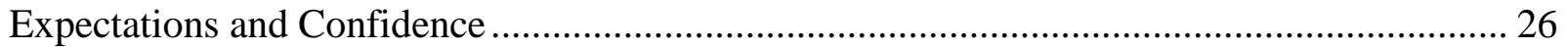

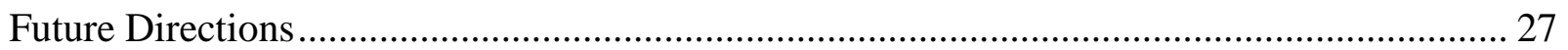

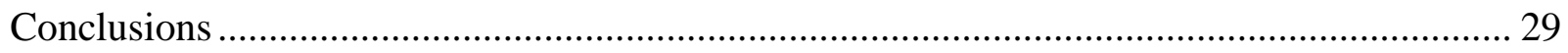




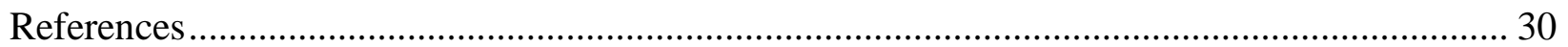

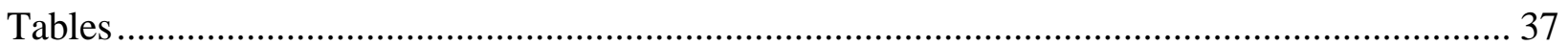




\section{Introduction}

Improving the accuracy of eyewitness testimony is an important application of memory research. The testimony of eyewitnesses may greatly affect the verdict and consequently the lives of multiple people. For this reason, it is extremely important that eyewitness testimony is as complete and as accurate as possible. Eyewitness testimony may be inaccurate because individuals forget some details of an event shortly after it occurs (Winningham, Hyman, \& Dinnel, 2000). In addition, reconstructive memory processes lead individuals to recreate their memory of the event due to forgetting and incorporating information from other sources (Hudson, 1990; Krackow, in press). Therefore, researchers have devised a variety of memory enhancement techniques aimed at improving the amount and accuracy of recall.

\section{Focused Meditation}

One memory enhancement technique that has been studied is focused meditation. The technique is based on two characteristics of hypnotic techniques including a relaxed state of mind via focus on a neutral target, such as breathing, and also instructs people to disregard distractions (Wagstaff, Brunas-Wagstaff, Cole, \& Wheatcroft, 2004). Both characteristics of hypnosis have been associated with improvements in memory (Wagstaff \& Mercer, 1993). The focused meditation technique requires individuals to listen to a 1.5 minute audio recording of a focused breathing mediation (Wagstaff, Brunas-Wagstaff, Cole, \& Wheatcroft, 2004). Then, individuals are asked to continue breathing in this manner and to focus during the recall of the to-be-remembered events.

In the first study that examined the efficacy of focused mediation, the authors utilized this procedure in a study of face recognition (Wagstaff, Brunas-Wagstaff, Cole, \& Wheatcroft, 2004). Participants in the focused meditation and control conditions were asked to recall faces 
they were shown earlier. Specifically, participants were given 30 seconds to study pictures of faces. They were then asked to engage in a questionnaire filler task for 10 minutes,; the exact nature of the task was not specified by Wagstaff et al. (2004). Following the 10 minute delay, participants in the focused meditation condition were given the intervention. Then all participants were asked to pick the appropriate faces they were shown earlier from the line-up array. There was a statistically significant effect of higher accuracy regarding correct recognition of faces in the focused meditation condition.

The efficacy of the focused meditation technique was further explored in a study that examined the influence of focused mediation and eye closure on memory recall of Princess Diana’s funeral (Wagstaff, Brunas-Wagstaff, Cole, Knapton, et al., 2004). Participants were randomly assigned to a control or a focused meditation condition, and within each condition participants were randomly assigned to an eyes closed or eyes opened condition. In the eyes closed condition, individuals closed their eyes throughout the meditation condition or control task, and through most of the memory task. In the eyes open condition, individuals kept their eyes open the whole time. Participants were asked open- and close-ended questions. Results for open-ended recall indicated a greater number of correct details and fewer incorrect details in the focused meditation condition. Further, eye closure supported, but did not completely account for, the influence of focused meditation on recall. These results support the conclusions drawn in the first focused meditation efficacy study (Wagstaff, Brunas-Wagstaff, Cole, \& Wheatcroft, 2004), namely that focused meditation was associated with higher accuracy of correct recognition.

However, the researchers were concerned that characteristics of the focused meditation technique (e.g., greater expectancies) may have led individuals to perform well, much like demand characteristics do for hypnosis techniques (Wagstaff, Brunas-Wagstaff, Cole, Knapton, 
et al., 2004). Therefore, they conducted a study in which they controlled for demand characteristics (Wagstaff, Brunas-Wagstaff, Cole, Knapton, et al., 2004). The focused meditation group actually scored lower, indicating that the results of the prior experiment were not solely due to performance expectancies.

The focused meditation technique has also been compared to context reinstatement in an examination of memory facilitation in children and adults (Hammond, Wagstaff, \& Cole, 2006). The same focused meditation procedure previously described was used, and the context reinstatement intervention consisted of listening to directions from the context reinstatement section of the original cognitive interview (Geiselman, Fisher, MacKinnon, \& Holland, 1985). The cognitive interview is a collection of interviewing techniques utilized by police investigators to efficiently and effectively interview witnesses (Fisher, Ross, \& Cahill, 2010). Context reinstatement is one of the techniques employed in the cognitive interview to improve memory performance. In this study, individuals in both conditions were compared to a control group that did not receive any intervention. Participants watched footage of a robbery and then answered open and close-ended questions about the film two days later. Both focused meditation and context reinstatement were associated with improved recall compared to the control condition, with results indicating greater recall in the context reinstatement condition than focused meditation. Both of these techniques were found to improve memory in children and adults.

Lastly, Wagstaff, Cole, Wheatcroft, Marshall, and Barsby (2007) evaluated the efficacy of a combined context reinstatement and focused meditation procedure on episodic memory, compared to a context reinstatement procedure alone. Previous studies by these researchers have shown that focused meditation improves recall without increasing the number of errors an individual makes, whereas context reinstatement has been shown to increase inconsistencies in 
recall (Hammond et al., 2006; Wagstaff, Brunas-Wagstaff, Cole, Knapton, et al., 2004). Therefore, the researchers were interested in whether combining these two techniques could improvement recall. Results of the study indicated that the combination of focused meditation and context reinstatement did improve episodic memory without also increasing recall errors. The context reinstatement alone condition was not shown to facilitate episodic memory. This suggests that a combined focused meditation and context reinstatement technique is more effective in improving episodic memory than a context reinstatement technique alone.

\section{Motivational Instructions}

A second promising memory enhancement technique is motivational instructions. This technique involves explicitly telling the participants that if they concentrate and do their best they will be able to remember. The technique was developed by Steven Jay Lynn and first published by Krackow, Lynn, and Payne (2005-2006) in their study on the effect of memory enhancement techniques on flashbulb memories. Motivational instructions may improve recall for two reasons. First, motivational instructions motivate participants to recall the event. Although only one prior published study has utilized motivational instructions as a memory enhancement technique, previous research has shown that motivation impacts memory accuracy. When participants are offered incentives for their correct recall, to increase motivation, their recall is more accurate than control groups who do not receive these rewards (Dougherty \& Harbison, 2007; Festinger et al., 2009; Roebers, Moga, \& Schneider, 2001; Seidler \& Howie, 1999). This effect was shown to hold for both children and adults (Seidler \& Howie, 1999; Roebers, Moga, \& Schneider, 2001). Second, motivational instructions create expectancies that participants will be successful if they try their best to recall the event. Motivation has also been shown to influence memory expectancies. Expectancies shape how individuals perceive, 
process, interpret, and remember events (Hirt, Lynn, Payne, Krackow, \& McCrea, 1999). Memory is influenced by expectancies, with individuals recalling information consistent with their expectancies (McDonald \& Hirt, 1997). It is also the case that psychological interventions such as antidepressants or memory interventions work when people expect them to (Kirsch \& Lynn, 1999).

In the first published study examining the effects of motivational instructions, Krackow et al. (2005-2006) examined the influence of hypnosis, context reinstatement, and motivational instructions (MI) on participants' recall of an emotionally-salient event. The MI was used as a control condition. MI was employed because it is often used as a control in hypnosis studies. It is used to counter the enhanced motivation inherent to hypnotic research because of the expectations of hypnotic performance as well as the performance demands inherent to hypnosis (Krackow et al., 2005-2006). In this study, participants recorded their memories of learning the news of Princess Diana's death. Approximately 3 months later, they returned to the lab and either received a hypnotic induction, context reinstatement/reverse order recall, or motivational instructions. Motivational instructions were embedded in all conditions. Participants receiving MI alone recalled significantly more episodic ideas in open-ended recall at Time 2 than at Time 1. Further, participants in the MI condition reported more consistent recollections than those in the hypnosis or context reinstatement/reverse order recall condition from Time 1 to Time 2. Therefore, the authors concluded that the use of a motivational instructions memory enhancement technique may produce more accurate and consistent recall than context reinstatement and hypnosis techniques (Krackow et al., 2005-2006). The motivational instructions technique was utilized in the current study to further examine the method's benefits over a no-motivational instructions control group. 


\section{Other Well-Researched Memory Enhancement Techniques}

It is briefly worth noting that there is the popular belief that hypnosis should be used to improve memory reports in forensic contexts. However, there is now an abundance of research to suggest the opposite- - hypnosis should not be used as a memory enhancement technique_-and in some states hypnotically elicited recall has been banned from the courtroom. Generally speaking hypnosis has been found to increase incorrect recall or inconsistent recall and increases confidence in that incorrect recall of both emotional and unemotional events (see Lynn, Lock, Myers, \& Payne, 1997, for a review; Krackow et al., 2005-2006).

A second frequently used memory enhancement technique is context reinstatement, which has been used alone or as a component of other memory recovery techniques. The context of a memory refers to an individual's external surroundings when an event occurred and was committed to memory (Smith \& Vela, 2001; Tulving \& Thompson, 1973). The context reinstatement technique is based on the idea that presenting the same cues during encoding and retrieval may improve recall (Tulving \& Thompson, 1973).

Shapiro and Penrod's (1986) meta-analysis of eyewitness identification and facial recognition studies found that context reinstatement had one of the largest influences on correct recognition, impacting both encoding and retrieval $(d=1.91)$. In their meta-analysis of seventyfive previous studies, Smith and Vela (2001) also found a significant effect size indicating that context did have an effect on memory $(d=.23$; $95 \% \mathrm{CI}+.06, n=93)$, but this effect is small. Finally, it should be noted that in some studies (Krackow et al., 2005-2006; Krafka \& Penrod, 1985; Malpass \& Devine, 1981) context reinstatement does not always improve memory accuracy and is sometimes detrimental to recall. Considering the evidence that context reinstatement increases memory inconsistencies and much smaller effect size for nonfacial 
recognition studies, we did not include context reinstatement as a memory enhancement technique in the current study. We concentrated on the motivational instructions and focused meditation techniques, as there is no evidence to date that these techniques increase memory errors.

\section{Source Monitoring}

There are several different types of eyewitness memory recall tasks, including openended questions, correctly misleading yes or no questions, incorrectly misleading yes or no questions, photographic line-ups, and source monitoring. Source monitoring refers to the cognitive task of tracing memories to their origins. Johnson, Hashtroudi, and Lindsay (1993) described source monitoring as "the set of processes involved in making attributions about the origins of memories, knowledge, and beliefs” (pg. 3). When a mental event is assigned an origin, the source falls into one of several source categories including but not limited to "perception, memory, dreaming, imagination, belief” (Mitchell \& Johnson, 2009). The event is also assigned a specific source, such as the specific person from which you heard a story (Mitchell \& Johnson, 2009). A source monitoring error occurs when the origin of a memory is attributed to a time, place, or person that is not the actual memory source. For example, an individual may incorrectly recall that they heard a piece of news from Ria when in fact they heard it from Kristina. Johnson et al. (1993) referred to this mistake as source misattribution.

In order to understand how a source monitoring error occurs, the elements that influence the accuracy of source attribution must be examined. There are two main factors that influence an individual's ability to appropriately identify a memory event’s source. The accuracy of source monitoring is contingent on the detail that is originally encoded about the event when the memory is formed (Johnson et al., 1993). The strength of the memory at encoding impacts the 
accuracy of source monitoring activities. Source monitoring accurateness is also influenced by processes carried out during the source monitoring task (Johnson et al., 1993). Accuracy is determined by "the quality of the decision processes" that are utilized when source monitoring evaluations are made (Johnson et al., 1993). It is not expected that one will be able to immediately recall a memory event that is marked with the exact source from which it originated (Johnson et al., 1993). More often, it is expected that individuals will remember information about a memory and then use decision making processes while recalling the event to correctly attribute source (Johnson et al., 1993). This framework emphasizes the importance of the decisions that are made with the recalled memory details. It follows that source monitoring will be disturbed or impaired by anything that interrupts these decision making processes (Johnson et al., 1993).

Aspects of the source memory task or test influence individuals' source monitoring abilities. A source monitoring test may improve attribution of source more than a yes-no recognition test because the instructions included in a source monitoring test remind individuals that the information they are being presented with could come from multiple sources (Multhaup, de Leonardis, \& Johnson, 1999; Dodson \& Johnson, 1993; Lindsay \& Johnson, 1989). The number of times individuals are exposed to misleading suggestions impacts monitoring of source, and repeated exposures to misleading information were associated with a greater number of source monitoring errors (Mitchell \& Zaragoza, 1996; Zaragoza \& Mitchell, 1996). Further, participants who were forced to confabulate information about a witnessed event later developed false memories that included this confabulated information as part of the event (Zaragoza, Payment, Ackil, Drivdahl, Beck, 2001). This suggests that participants had difficulty monitoring the source of their memories as originating from the actual event or their own confabulations. 
Additionally, characteristics of the individual have also been shown to impair source monitoring ability. Children have been found to be less accurate in their source monitoring than adults, with their source monitoring ability improving from childhood to mid-life and then declining (Ackil \& Zaragoza, 1998; Ackil \& Zaragoza, 1995; Poole \& Lindsay, 1995; Poole \& Lindsay, 2001; Poole \& Lindsay, 2002; Lindsay, Johnson, \& Kwon, 1991). Older adults have been found to have greater difficulties with source monitoring than younger and middle-aged adults, which may be due to deficiencies in encoding and monitoring their memories (see Ferguson, Hashtroudi, \& Johnson, 1992; Hashtroudi, Johnson, Chrosniak, 1989; Hashtroudi, Johnson, Vnek, \& Ferguson, 1994; Henkel, Johnson, de Leonardis, 1998; Johnson, 2006; Johnson, de Leonardis, Hashtroudi, \& Ferguson, 1995; Mitchell, Johnson, \& Mather, 2003; Mitchell, Johnson, Raye, Mather, D’Esposito, 2000; Schacter, Koutstaal, Johnson, Gross, Angell, 1997; ). Traumatic brain injury has also been associated with impairments in source monitoring (Johnson \& Raye, 1998; Mitchell \& Johnson, 2009).

Finally, elements of individuals' attention and prior choices can impact source attributions. Individuals make source monitoring errors that are congruent with choices they have made, so that their memory supports these choices (Mather, Shafir, \& Johnson, 2000). For example, if a person has dined at a particular restaurant, they might inaccurately attribute positive reviews to the chosen restaurant and negative reviews to a different restaurant. This choice-supportive memory increases with age (Mather \& Johnson, 2000). When people hear the same information from two different sources during a short time period, they also make source monitoring errors (Krackow et al., 2005-2006). Further, the attention given to a source monitoring task influences the accuracy of source attributions. Individuals who had limited attentional resources, either when hearing misleading suggestions or making source judgments, 
were found to make more source monitoring errors than those who could give their full attention to the task (Zaragoza \& Lane, 1998).

\section{Current Study}

The main goal of the current study was to further examine the efficacy of motivational instructions in improving recall. One earlier study suggested that this intervention held the greatest promise with respect to increasing recall without increasing inaccurate recall. However, the empirical question remained as to whether providing people with motivational instructions increased recall above and beyond a no-intervention control condition. A second goal of the proposed study was to examine the memory enhancement techniques using a source monitoring task as the outcome measure. Previous studies have included numerous memory measures as outcomes, but have not examined the effects of these techniques on source monitoring. A third goal of the study was to continue to examine the efficacy of focused mediation. To date, extant studies showing its efficacy were conducted by only one principle investigator. Finally, the proposed investigation allowed each memory enhancement technique to be compared to one another to assess increases in correct and incorrect recall.

In the current study, participants viewed a forensically relevant to-be-remembered event and immediately completed a questionnaire that introduced information from a second source. Two days later, participants returned and were randomly assigned to one of three memory enhancement techniques (focused mediation, motivational instructions, or a no-technique control condition). They then completed a source monitoring test and free recall memory task.

Based on the results of prior studies, the following hypotheses were made:

Hypothesis 1: Motivational Instructions were expected to be associated with a higher accuracy score on source monitoring and free recall tasks compared to a no-intervention control 
group. In a previous study, individuals in the MI condition were found to recall more information than those in other the context reinstatement and hypnosis conditions, both of which have been shown to increase accurate recall in numerous studies (Krackow et al., 2005-2006).

Hypothesis 2: Focused mediation was expected to be associated with a higher accuracy score on source monitoring and free recall tasks compared to the control group. Several previous studies have shown that the focused meditation technique can improve recall beyond a control group or context reinstatement condition (Hammond et al., 2006; Wagstaff et al., 2007; Wagstaff, Brunas-Wagstaff, Cole, Knapton, et al., 2004; Wagstaff, Brunas-Wagstaff, Cole, \& Wheatcroft, 2004). Subsequently, participants in the focused mediation condition were expected to perform better on a source monitoring task than participants who had not received a memory enhancement intervention.

Hypothesis 3: Motivational instructions were expected to be associated with a higher accuracy score on source monitoring and free recall tasks compared to scores in the focused meditation experimental group. Previous studies have demonstrated larger effect sizes of motivational instructions on accurate recall compared to the effect of focused meditation (Hammond et al., 2006; Krackow et al., 2005-2006; Wagstaff et al., 2007; Wagstaff, BrunasWagstaff, Cole, Knapton, et al., 2004; Wagstaff, Brunas-Wagstaff, Cole, \& Wheatcroft, 2004).

\section{Method}

\section{Participants}

Participants were 68 undergraduate students taking a psychology course at West Virginia University. Fifty-nine participants completed both sessions $(n=59)$. Only data from participants who completed both sessions were included in analyses, because the experimental manipulation and memory tasks occurred in the second session. There were 19 participants in 
the control condition, 21 participants in the focused meditation condition, and 19 participants in the motivational instructions condition. Participants ranged in age from 18 to 30 years $(M=$ 20.76). Sixty-one percent of participants were female. The sample consisted of primarily college seniors (57.6\%), but also included freshman (10.2\%), sophomores (10.2\%), and juniors (22\%). Participants self-identified as 91.5\% Caucasian, 3.4\% African American, 3.4\% Hispanic, and $1.7 \%$ Asian.

Participants were given the opportunity to partake in the study during in their undergraduate psychology courses at West Virginia University. Participation was voluntary, and occurred during the last half of two consecutive class periods. Therefore, all participants were run in groups in three different undergraduate courses. All sessions occurred in the Life Sciences Building. This recruitment and administration procedure was approved by the West Virginia University Internal Review Board.

\section{Procedure}

\section{Design overview.}

Each participant partook in two study sessions scheduled two days apart. The procedure for each session is detailed below. A summary of the source monitoring task developed by Zaragoza is as follows: In session 1, participants were told that they were participating in a study on college students’ memory. Information from two sources was presented, a video and a

questionnaire. The video depicted a forensically relevant event. Immediately following the video, participants completed a questionnaire that asked 36 questions, some of which inquired about details consistent with the video and some which included details inconsistent with the content of the video. In session 2, participants received a memory enhancement technique or no technique. Immediately following, participants received a source monitoring test. Different researchers ran 
the first and second sessions. A trained graduate research assistant ran the first session. Graduate students and an experienced undergraduate student ran the second session to maximize the researchers' credibility and the participants' confidence in the memory enhancement techniques. A more detailed description of the procedure follows below and is depicted in Figure 1.

\section{Session 1.}

All participants from the same psychology class were run in the same room at the same time for this session. At the beginning of this session, participants completed the consent form. At this time, the participants were informed that they were participating in a memory study. They also completed a demographic questionnaire that inquired about their age, sex, ethnicity, and year in college.

\section{Source monitoring video.}

Participants viewed the eyewitness event. The event was a 5 minute video of two men committing a burglary and a resulting car chase by police (Zaragoza \& Mitchell, 1996). The video was originally part of a police training video and has been used previously in source monitoring studies (Zaragoza \& Mitchell, 1996; Mitchell, Johnson, \& Mather, 2003).

\section{Source monitoring questionnaire.}

Immediately following the video, participants completed the questionnaire that served as the second source of information in the experiment. The purpose of the questionnaire was to review the events from the video and to introduce new information that was not found in the video. This new information aligned closely with the scenes that were viewed.

The questionnaire was created by Mitchell and Zaragoza for use with the event video (Mitchell, Johnson, \& Mather, 2003). This questionnaire contained 36 questions about the 
events viewed on the video. There were three subsets of questions consisting of 12 items each. Within the subsets each question corresponded to one of twelve specific events from the video. Each question reiterated the main premise of the event, and then focused on a distinct aspect of the event and provided information not found in the other questions.

Participants were instructed to answer each question in order and without looking back at previous items. Participants were also directed to answer every question without skipping any items. They were told to make their best guess if they were unsure of an item. Participants were directed to answer each question using no more than two or three words because most items can be answered with a “yes” or "no”.

Following the completion of this questionnaire the researcher reminded the participants that session two would occur during the same time period in two days. Participants were instructed not to share the details of the experiment with other students as they may be participants in the future. The first session of the experiment took approximately 20 minutes.

\section{Session 2.}

\section{The experimental memory enhancement interventions.}

In the beginning of the session each participant was randomly assigned to one of three memory enhancement conditions: motivational instructions, focused meditation, or nointervention control. These conditions are discussed below. Roughly equal numbers of participants were randomized to each condition from each of the three psychology courses. Randomization took place in the original classroom where the course was held and the first session occurred. Then, all participants for each condition were relocated to a different room for the completion of the session.

Motivational instructions protocol (Krackow, Lynn, and Payne, 2005-2006): 
In this condition, participants were told to "try your best to recall the video and the details contained in the questions you answered immediately following the video. If you concentrate and do your best to recall the video and the details contained in the questions you answered immediately following the video, you will be able to do so even if it requires some effort.”

Focused meditation protocol (Wagstaff, Brunas-Wagstaff, Cole, \& Wheatcroft, 2004):

In this condition, researchers led the participants through a short focused-breathing meditation exercise. Participants were instructed to sit comfortably, naturally breathe in and out, and focus on their breathing. They were asked to remain aware and focused but to continue to concentrate on their breathing. They were reminded to bring their attention back to their breathing if their mind began to wander. They were asked to continue focusing on their breathing during the instructions and during the next part of the experiment (source memory test). The nature of the meditation may lead participants to close their eyes during the intervention; however, participants were instructed to keep their eyes open. Manipulating eye closure has been found to be successful in increasing accurate recall, so participants were asked to keep their eyes open throughout the meditation to minimize the influence of eye closure on memory (Wagstaff, Brunas-Wagstaff, Cole, Knapton, et al., 2004; Perfect et al., 2008).

\section{Control protocol:}

Participants in the control condition did not receive any intervention and proceeded directly to the expectancy rating and source memory test.

\section{Expectancies ratings.}

Participants were asked to rate the extent to which they expected the intervention they received would improve their memory. A single intervention-specific item was used to assess expectancies, with a scale that ranged from not at all (1) to very much (5). Participants in the 
control condition also completed an expectancy item that asked "How much do you expect you will be able to remember?” Krackow et al. (2005-2006) previously used expectancy items to assess the effect of interventions anticipated by participants.

\section{The source memory test.}

Immediately after the intervention, the participants completed the source memory test. The score on the source memory test was a primary outcome measure of the experiment. This measure was created by Zaragoza and colleagues for use with their experimental source monitoring task (Mitchell, Johnson, \& Mather, 2003). Participants listened to 32 audio recorded statements read at 8 second intervals. For each statement, participants marked whether the item was found only in the video, only in the written questions they completed after the video, in both the video and the written questions, or in neither the video nor the written questions. For each statement, participants also indicated whether or not their answer was a complete guess, meaning they had no idea what the correct source of the memory was and randomly responded to the question. If the participant marked the correct origin of the statement, the item was scored as correct; if an incorrect origin was selected, the item was scored as incorrect. A participant's total correct score on the measure is a dependent variable of interest.

Participants reviewed written instructions for the source memory test that were also read aloud by the researcher. Participants were directed to make their source judgments based on their own memory of session one. As part of the instructions, they were explicitly told that the items may come from the video, the questions, both, or neither. All participants were given the opportunity to ask questions about the instructions, and the researcher did not proceed with the test until it was clear that the participants understood the task. 


\section{The free recall task.}

Participants' written open-ended recall of the video was obtained. Participants were asked to describe their complete, detailed memory of what happened in the video. Memory reports were coded for the accuracy of each individual idea unit that was included, specifically whether each statement was correct or incorrect. An idea unit is the smallest phrase written that includes a verb and could stand on its own as a sentence. A correct idea unit accurately states something that was observable in the five minute event video. An incorrect idea unit inaccurately states something that was not observable in the event video, including anything introduced by the source monitoring questionnaire. This coding system was developed by Elisa Krackow and has been used in multiple studies to code free recall memory data (e.g., Krackow et al., 2005-2006). One coder reviewed all the free recall data, after establishing good reliability on $25 \%$ of the memory reports with two coders previously trained in the coding system. The number of total correct idea units is a dependent variable of interest.

\section{Confidence ratings.}

Participants completed a confidence rating item for each memory task that asked them to assess their confidence in their overall accuracy on each task. The source memory test item asked participants "How confident are you in the accuracy of your answers to the questions you just completed?” The free recall task item asked “How confident are you in the accuracy of your memory report?” For both items, participants rated their confidence on a scale from not at all confidence (1) to extremely confident (7).

\section{Debriefing.}

Immediately following the source test, participants were debriefed and the study’s focus on source monitoring was explained. Although participants were told that they were involved in 
a memory study from the beginning of the first session, they were not informed that it was a study of memory source. In real life situations, individuals view an unexpected event and are later asked to recall what they experienced and determine the appropriate origin of their memories as part of an investigation. They are obviously not warned prior to the event that they should be ready to monitor the source of their memories. Therefore, not revealing the source monitoring focus of the study allowed the results to more closely approximate individuals' performance in actual eyewitness settings. However, participants were told that they were participating in a memory study to increase their motivation and attention throughout the two study sessions. After the debriefing, participants were given the opportunity to ask any questions about the study procedures. They were also reminded to not discuss any events of the study with others at the university, because other students may participate in the study at a later time.

\section{Results}

\section{Source Monitoring Accuracy}

See Table 1. An analysis of variance was performed to determine if there were differences in source monitoring accuracy across the three conditions. There was no effect of memory enhancement intervention on total source monitoring accuracy scores, $F(2,56)=0.264$, $p=.769$. There was no evidence that source monitoring accuracy was higher in the focused meditation condition $(M=14.80, S D=3.09)$ or the motivational instructions condition $(M=$ 14.26, $S D=2.64)$ compared to the control condition $(M=14.21, S D=2.95)$. Post hoc Tukey tests did not reveal any significant differences in source monitoring accuracy between the three conditions.

See Table 2. The source monitoring task consisted of four different types of questions based on misleading information read in the source monitoring questionnaire; information seen 
in the video; information seen in the video and read in the questionnaire; and new information that was not seen in the video nor saw in the questionnaire. Analyses of variances were used to clarify if participants' source monitoring accuracy on each type of questions differed across the three conditions. There was no effect of type of question on source monitoring accuracy for questions pertaining to misleading information $(F(2,56)=.485, p=.618)$, seen information $(F(2,56)=.436, p=.649)$, or information seen and read in the questionnaire $(F(2,56)=.595, p=$ .555). There was a significant effect of question type on source monitoring accuracy for questions presenting new information, $F(2,56)=4.447, p=.016$. Participants in the focused meditation condition $(M=3.76, S D=.43)$ more often correctly recognized the questions containing new information and labeled them appropriately compared to participants in the motivational instructions $(M=3.21, S D=.71)$ or control $(M=3.42, S D=.60)$ conditions. Post hoc Tukey tests indicated that the difference in source monitoring accuracy for questions containing new information was significantly different between participants in the motivational instructions and focused meditation groups $(p=.013)$, with participants recognizing more new information accurately in the focused meditation condition.

\section{Free Recall Memory Accuracy: Correct and Incorrect Recall}

See Table 3. Analyses of variance were performed to determine if there were differences on the number of correct ideas recalled in free recall across the three conditions, $F(2,56)=$ 3.291, $p=.045$, partial eta squared $=.105$. Planned comparisons were completed to test the specific hypotheses of the study. Participants in the focused meditation condition were not found to recall significantly more accurate ideas than participants in the control condition, $t(31.33)=$ $.083, p=.934$ nor were motivational instructions significantly different from control, $t(34.75)=$ 1.97, $p=.056$. Note that the Levene statistic indicated a violation and therefore the $\mathrm{df}$ values 
were 31.33 and 34.75 in two just-reported analyses. Planned comparisons were run again without the data from one individual in the motivational instructions group discussed who only reported two ideas on the free recall task. When data from the individual who only reported 2 ideas was removed, the results were identical, $F(2,55)=2.368, p=.103$, partial eta squared $=.079$. Participants in the motivational instructions condition did not recall significantly fewer accurate ideas than participants in the control $(t=-1.91, p=.061)$ or the focused meditation condition $(t=$ 1.88, $p=.065)$.

There was no effect of memory enhancement intervention on number of incorrect ideas recalled, $F(2,56)=1.134, p=.329$, partial eta squared $=.039$.

\section{Expectancies}

See Table 4. An analysis of variance was also performed to clarify if there were differences in participants' expectations about the effectiveness of the interventions. There was an effect of condition on participants' expectations of how much the condition would improve their memory, $F(2,56)=6.46, p=.003$, partial eta squared $=.188$. Participants in the control condition $(M=3.15, S D=.50)$ had a greater expectation that they would be able to recall accurately compared to participants in the focused meditation condition $(M=2.33, S D=.96)$ or motivational instructions condition $(M=2.94, S D=.70)$. Post hoc Tukey tests showed that participants in the focused meditation condition had significantly lower expectations that the techniques would improve their recall accuracy compared to participants in the motivational instructions $(p=.035)$ and control conditions $(p=.003)$.

\section{Confidence}

Analyses of variance were performed to determine if there were differences in participants' confidence in their accuracy on the two memory tasks. There was no effect of 
memory enhancement intervention on participants’ confidence ratings of their accuracy on the source monitoring task, $F(2,56)=.164, p=.849$. There was also no effect of memory enhancement intervention on participants' confidence ratings of their accuracy on the free recall memory task, $F(2,56)=1.66, p=.200$.

\section{Discussion}

The current study examined the effects of two memory enhancement techniques on source monitoring and open-ended recall. Specifically, the study hypothesized that the focused meditation and motivational instructions techniques would each produce higher accurate recall on the source monitoring test and free recall task compared to a no-intervention control condition without also increasing incorrect recall. It was also hypothesized that motivational instructions would produce a higher accuracy score on both tasks compared to the accuracy score produced by the focused meditation technique. The results of the current study do not support these hypotheses. These results are contrary to previous studies on focused meditation and motivational instructions which found a positive effect of these techniques on memory.

\section{Source Monitoring}

The focused meditation and motivational instructions techniques were not found to increase source monitoring accuracy compared to the control group on the source monitoring task. These techniques were predicted to improve source monitoring because they have been shown to increase accurate recognition and recall in other memory tasks (Hammond, Wagstaff, \& Cole, 2006; Wagstaff, Brunas-Wagstaff, Cole, \& Wheatcroft, 2004; Wagstaff, BrunasWagstaff, Cole, \& Wheatcroft, 2004; Wagstaff, Cole, Wheatcroft, Marshall, \& Barsby, 2007; Krackow et al., 2005-2006). It was expected that if these techniques were effective with openended recall and facial recognition tasks, they would also improve memory in a source- 
monitoring specific task. The results suggest that focused meditation and motivational instructions are not effective techniques for improving source memory, at least when this particular source memory task is utilized. Improving concentration and motivation may not be sufficient to increase source monitoring accuracy, and interventions that directly target source monitoring processes may be more appropriate (see Giles, Gopnik, \& Heyman, 2002).

The source monitoring task consisted of presentation of statements containing information that was either presented in several contexts (video, questionnaire, video and questionnaire) or was new. Participants then had to respond to questions which asked them to indicate the specific source or whether the information was never encountered in the context of this study. When the source monitoring task was broken down into questions that tapped information-source-specific statements, there was only an intervention effect for questions that inquired about new information, which was information not contained in the video nor the questionnaire that followed the video. Participants in the focused meditation condition were more likely to answer these questions correctly (i.e. recognize that they contained new information) than participants in the motivational instructions condition. This effect of focused meditation on participants' accuracy in answering questions containing new information should be interpreted cautiously. Only 4 out of 32 statements contained new information, which was less than the other types of statement categories. Further, the majority of participants answered 3 or 4 questions correctly, with only two participants answering 2 of 4 questions correctly. Consequently, there was only a one question difference on this question type for most participants. This suggests that although the effect of focused meditation was statistically significant, it may not have a practical impact on source monitoring performance. 
Generally, it would only be appropriate to examine the effect of each condition on question type if there was an effect of condition on total source monitoring accuracy because these further analyses would be able to explain which question types were driving the effect. Even when the analysis of question type was completed, the result conflicted with what would logically be expected regarding the source monitoring task. An effect of condition on questions regarding information seen in the video or read in the questionnaire would be expected because the memory enhancement techniques were employed to impact participants' memories of the video and of the questions contained in the questionnaire they responded to immediately following the video. An effect on these questions would suggest that the technique improved monitoring between the two different sources of information. However, the actual obtained effect on new information questions indicates that focused meditation did not improve monitoring of source at all, but only improved recognition that participants had not heard the new information before in any way. This interpretation that focused meditation improved general memory ability aligns with previous research regarding focused meditation. Focused meditation has been associated with higher accuracy on recognition memory tasks (Hammond, Wagstaff, \& Cole, 2006; Wagstaff, Brunas-Wagstaff, Cole, \& Wheatcroft, 2004). Focused meditation also emphasizes concentration and ignoring distractions, which is likely to help participants distinguish information they have never heard previously (Wagstaff, BrunasWagstaff, Cole, \& Wheatcroft, 2004).

Memory enhancement techniques that target source monitoring specific retrieval processes may be more beneficial in improving source monitoring accuracy than interventions that target general memory abilities. Very little research is available regarding interventions that are effective specifically with source monitoring. One promising technique that has been shown 
to improve source monitoring accuracy is source monitoring training. In one version of source monitoring training, participants reviewed the events from multiple sources (from two different sources) and explicitly reported where each occurred (for example, in real life or on television) (Thierry, Lamb, Pipe, \& Spence, 2010; Thierry \& Spence, 2002, see also Giles, Gopnik, \& Heyman, 2002). Although source monitoring training has been primarily studied with children, there is evidence that it may be an effective technique to improve source monitoring accuracy. Preschool children who received source monitoring training were more accurate in determining source in response to close- and open-ended questions than children who received control training (Thierry, Lamb, Pipe, \& Spence, 2010; Thierry \& Spence, 2002). Source monitoring training also reduced the extent to which 7- and 8-year-old children falsely attributed events to the wrong source (Poole \& Lindsay, 2002). Thierry et al. (2010) suggest that source monitoring training is effective because it shows participants that specific contextual details can be used to accurately determine source. Therefore, it may be more useful to focus on source monitoring interventions that directly target the cognitive processes through which source memories are retrieved, rather than attempting to improve overall memory abilities through techniques such as focused meditation and motivational instructions. Future research into source monitoring interventions may examine the use of source monitoring training with other age groups and more forensically relevant materials.

\section{Free Recall Memory Accuracy}

The focused meditation and motivational instructions techniques also did not increase recall of correct ideas on the free recall memory task. These techniques were predicted to increase accurate recall because previous research shows that they have successfully increased accurate open-ended recall without also increasing inaccurate recall. Similar effects of the two 
techniques were expected to be found in the current study because the free recall memory report task is similar to open-ended recall tasks used in previous studies. In addition, the results of the current study indicate that focused mediation and motivational instructions did not increase inaccurate recall compared to the control condition.

The finding that focused meditation did not increase recall of accurate memory ideas does not align with previous research. Although only a few studies have been conducted examining the effectiveness of focused meditation, each study has shown that the technique increases accurate recognition or recall on closed- and open-ended tasks (Hammond et al., 2006; Wagstaff, Brunas-Wagstaff, Cole, Knapton, et al., 2004; Wagstaff, Brunas-Wagstaff, Cole, \& Wheatcroft, 2004; Wagstaff, Cole, Wheatcroft, Marshall, \& Barsby, 2007). In some cases the impact of focused meditation was not the greatest effect in the study. For example, in one study the context reinstatement technique was found to have a greater effect on accurate recall than focused meditation (Hammond et al., 2006), and in another the combination of context reinstatement and focused meditation had a greater effect on increasing accurate recall than context reinstatement alone (Wagstaff, Cole, Wheatcroft, Marshall, \& Barsby, 2007). However, in each study focused meditation was found to have some effect of increasing accurate recognition or recall. Therefore, it was expected that the focused meditation condition in the current study would have some impact on increasing recall of accurate ideas on the free-recall memory report. The actual finding does not show this and is very unexpected.

The lack of intervention efficacy in the current study may be due to study design rather than characteristics of the techniques. Previous studies have shown focused meditation to have an effect on increasing memory accuracy in multiple situations. Although only one previous published study has examined motivational instructions, it showed a strong effect on memory 
accuracy. In addition, two previous unpublished studies from Steven Lynn’s lab corroborated this result (Kvinge, 1986; Penzien, 1985). Therefore, it is possible that the lack of effects in the current study is due to the short time frame between the two study sessions. There were only 48 hours between the time the participants viewed the video and when they completed the free recall task. That may not have been enough time for participants to begin "forgetting” this particular video and for the memory enhancement techniques to serve as useful interventions. As the results show, most participants performed relatively equally no matter their condition on both memory tasks, suggesting that recall was similar for all participants.

\section{Expectations and Confidence}

Participants were asked to rate their expectations regarding the extent to which they believed the interventions would improve their memory. Participants in the focused meditation condition were found to have significantly lower expectations that the intervention would improve their recall compared to participants in the other two conditions. It is reasonable that expectancies were higher in the motivational instructions condition compared to the focused meditation condition. The reason may be because motivational instructions actively attempt to increase expectations that one will remember accurately (Krackow et al., 2005-2006). The focused meditation technique focuses on relaxation and concentration, but does not specifically address motivation and expectations (Wagstaff, Brunas-Wagstaff, Cole, \& Wheatcroft, 2004). The result that expectancies were higher in the control condition than the focused meditation condition was unexpected.

It is possible that this unexpected expectancies result is due to differences in wording within the expectancies question. However, the wording was congruent for the two experimental conditions and therefore cannot explain the difference between focused meditation and 
motivational instructions. For the two experimental conditions, participants were asked to rate how much they expect that the intervention will improve their memory. In the control condition, participants were asked to rate how much they expect that they will be able to remember. The difference in wording between the conditions is because the control condition does utilize any intervention and therefore there is no intervention to ask about. However, it is possible that these two types of questions were assessing two different expectations. In particular, the intervention expectancies question may have been assessing expectancies regarding the efficacy of the interventions, and the control expectancies question may have been assessing expectancies regarding one’s own ability to remember. Participants may have been more confident in their own abilities to remember than in the ability of the interventions to improve their recall.

Lastly, participants’ confidence in the accuracy of their memories was assessed after each memory task. There was no effect of participants’ ratings of their confidence on their actual accuracy on the source monitoring task or the free recall memory task. These results suggest that how confident participants feel about their answers does not actually influence the accuracy of their memory reports. This is consistent with a large body of previous research showing that confidence does not predict memory accuracy (e.g., Neisser \& Harsch, 1993).

\section{Future Directions}

The results of the current study suggest that focused meditation and motivational instructions may not be effective interventions to increase accuracy on source monitoring memory tasks. However, previous research still supports the efficacy of these interventions for use with free-recall memory tasks. Although the current study did not find evidence to support the effects of these memory enhancement techniques, this may be due to procedural effects of the study. In particular, the study only used a 48 hour period between presentation of the to-be- 
remembered stimuli and the free recall task. This may not have been enough time for significant forgetting of this particular video to occur, and therefore the techniques were not effective interventions when less forgetting had occurred. Future studies should pilot the stimulus materials with different time intervals between the first and second session to ascertain when sufficient forgetting occurs. The use of a week between sessions may be practically feasible because it is often difficult to bring back participants after many months. Further, the use of a week interval may be more realistic and representative of actual memory challenges because in the real world individuals often have to recall information first viewed many days or weeks before.

The current study was also run in a group format, in three undergraduate psychology courses. Although this procedure worked relatively well and allowed for a large group of individuals to participate at once, there were also drawbacks associated with this procedure. In particular, some individuals may have felt rushed to finish before the class time ended. This may have been the case with one participant who completed much fewer ideas on the free recall memory report compared to other participants; data for this participant was removed during analysis. Running participants in sessions individually or in smaller groups may encourage participants to take their time and be more thorough in their completion of the free recall task.

Future studies may also use different stimulus materials, such as a longer more detailed crime video. The materials used in this study, including the crime video, were chosen because they are part of a well-tested source monitoring technique (Zaragoza \& Mitchell, 1996). However, if source monitoring is not included as a dependent variable, other videos could be used. A longer video with more ideas could also lead to more variability in participants’ 
answers. Any effects of the memory enhancement techniques may be clearer because there would be a larger range of ideas that participants could recall.

\section{Conclusions}

The current study examined the effects of focused meditation and motivational instructions on accurate recall on source monitoring and free recall tasks, compared to a nointervention control condition. Neither memory enhancement technique was found to improve accuracy on the memory tasks. None of the hypotheses of the proposed study were supported. There was an effect of condition on one source monitoring question type, presentation of new information, suggesting that focused meditation was effective in improving general memory accuracy by increasing concentration and focus. However, further experiments will have to examine this finding explicitly. Although few conclusions can be drawn from the current findings, they do show that conducting short memory enhancement techniques in an experimental study with a no-intervention control is feasible. The discussion provides guidance for future directions in the research, including explicit suggestions for changes to the study procedures. 


\section{References}

Ackil, J. K., \& Zaragoza, M. S. (1995). Developmental differences in eyewitness suggestibility and memory for source. Journal of Experimental Child Psychology, 60, 57-83. doi:10.1006/jecp.1995.1031

Ackil, J. K., \& Zaragoza, M. S. (1998). Memorial consequences of forced confabulation: Age differences in susceptibility to false memories. Developmental Psychology, 34, 13581372. doi:10.1037/0012-1649.34.6.1358

Dodson, C. S., \& Johnson, M. K. (1993). Rate of false source attributions depends on how questions are asked. The American Journal of Psychology, 106, 541-557. doi:10.2307/1422968

Dougherty, M.R. \& Harbison, J. I. (2007). Motivated to retrieve: How often are you willing to go back to the well when the well is dry? Journal of Experimental Psychology: Learning, Memory, and Cognition, 33, 1108-1117. doi:10.1037/0278-7393.6.1108

Ferguson, S. A., Hashtroudi, S., \& Johnson, M. K. (1992). Age differences in using sourcerelevant cues. Psychology and Aging, 7, 443-452. doi:10.1037/0882-7974.7.3.443

Festinger, D.S., Marlowe, D. B., Croft, J. R., Dugosh, K. L., Arabia, P. L., \& Benasutti, K. M. (2009). Monetary incentives improve recall of research consent information: It pays to remember. Experimental and Clinical Psychopharmacology, 17, 99-104. doi:10.1037/a0015421

Fisher, R. P., Ross, S. J., \& Cahill, B.S. (2010). Interviewing witnesses and victims. In P. Granhag (Ed.), Forensic psychology in context: Nordic and international approaches (pp. 56-74). Devon United Kingdom: Willian Publishing. Retrieved from EBSCOhost. 
Geiselman, R. E., Fisher, R. P., MacKinnon, D. P., \& Holland, H. L. (1985). Eyewitness memory enhancement in the police interview: Cognitive retrieval mnemonics versus hypnosis. Journal of Applied Psychology, 70, 401-412. doi:10.1037/0021-9010.70.2.401

Giles, J., Gopnik, A., \& Heyman, G. 2002. Source monitoring reduces the suggestibility of preschool children. Psychological Science, 13, 288-291.

Hammond, L., Wagstaff, G. F., \& Cole, J. (2006). Facilitating eyewitness memory in adults and children with context reinstatement and focused meditation. Journal of Investigative Psychology and Offender Profiling, 3(2), 117-130. doi:10.1002/jip.47

Hashtroudi, S., Johnson, M. K., \& Chrosniak, L. D. (1989). Aging and source monitoring. Psychology and Aging, 4, 106-112. doi:10.1037/0882-7974.4.1.106

Hashtroudi, S., Johnson, M. K., Vnek, N., \& Ferguson, S. A. (1994). Aging and the effects of affective and factual focus on source monitoring and recall. Psychology and Aging, 9, 160-170. doi:10.1037/0882-7974.9.1.160

Henkel, L. A., Johnson, M. K., \& De Leonardis, D. M. (1998). Aging and source monitoring: Cognitive processes and neuropsychological correlates. Journal of Experimental Psychology: General, 127, 251-268. doi:10.1037/0096-3445.127.3.251

Hirt, E. R., Lynn, S., Payne, D. G., Krackow, E., \& McCrea, S. M. (1999). Expectancies and memory: Inferring the past from what must have been. In I. Kirsch (Ed.), How expectancies shape experience (pp. 93-124). Washington, DC US: American Psychological Association. doi:10.1037/10332-004

Hudson, J. A. (1990). Constructive processing in children's event memory. Developmental Psychology, 26(2), 180-187. doi:10.1037/0012-1649.26.2.180 
Johnson, M. K. (2006). Memory and reality. American Psychologist, 61, 760-771. doi:10.1037/0003-066X.61.8.760

Johnson, M. K., De Leonardis, D. M., Hashtroudi, S., \& Ferguson, S. A. (1995). Aging and single versus multiple cues in source monitoring. Psychology and Aging, 10, 507-517. doi:10.1037/0882-7974.10.4.507

Johnson, M. K., Hashtroudi, S., \& Lindsay, D. (1993). Source monitoring. Psychological Bulletin, 114, 3-28. doi:10.1037/0033-2909.114.1.3

Johnson, M. K., \& Raye, C. L. (1998). False memories and confabulation. Trends in Cognitive Sciences, 2, 137-145. doi:10.1016/S1364-6613(98)01152-8

Kirsch, I., \& Lynn, S. J. (1999). Automaticity in clinical psychology. American Psychologist, 54, 504-515. doi: 10.1037/0003-066X.54.7.504

Krackow, E. (in press). The effects of writing on memory for a forensically relevant event. Imagination, Cognition, and Personality.

Krackow, E., Lynn, S., \& Payne, D. G. (2005-2006). The death of Princess Diana: The effects of memory enhancement procedures on flashbulb memories. Imagination, Cognition and Personality, 25(3), 197-219. doi:10.2190/FBCF-T8VG-L5LJ-N8VL

Krafka, C. \& Penrod, S. (1985). Reinstatement of context in a field experiment on eyewitness identification. Journal of Personality and Social Psychology, 49, 58-69. doi:10.1037/0022-3514.49.1.58

Kvinge, D. L. 1986. Memory enhancement in eyewitness testimony. Unpublished Doctoral Dissertation, Ohio University.

Lindsay, D., \& Johnson, M. K. (1989). The eyewitness suggestibility effect and memory for source. Memory \& Cognition, 17, 349-358. Retrieved from EBSCOhost. 
Lindsay, D., Johnson, M. K., \& Kwon, P. (1991). Developmental changes in memory source monitoring. Journal of Experimental Child Psychology, 52, 297-318. doi:10.1016/00220965(91)90065-Z

Lynn, S., Lock, T.G., Myers, B., \& Payne, D.G. (1997). Recalling the unrecallable: should hypnosis be used to recover memories in psychotherapy? Current Directions in Psychological Science, 6, 79-83. doi:10.1111/1467-8721.ep11512662

Malpass, R. S., \& Devine, P. G. (1981). Guided memory in eyewitness identification. Journal of Applied Psychology, 66(3), 343-350. doi:10.1037/0021-9010.66.3.343

Mather, M., \& Johnson, M. K. (2000). Choice-supportive source monitoring: Do our decisions seem better to us as we age? Psychology and Aging, 15, 596-606. doi:10.1037/08827974.15.4.596

Mather, M., Shafir, E., \& Johnson, M. K. (2000). Misremembrance of options past: Source monitoring and choice. Psychological Science, 11, 132-138. doi:10.1111/14679280.00228

McDonald, H. E. \& Hirt, E. (1997). When expectancy meets desire: Motivational effects in reconstructive memory. Journal of Personality and Social Psychology, 72, 5-23. doi:10.1037/0022-3514.72.1.5

Mitchell, K. J. \& Johnson, M. K. (2009). Source monitoring 15 years later: What have we learned from fMRI about the neural mechanisms of source memory? Psychological Bulletin, 135, 638-677. doi:10.1037/a0015849

Mitchell, K. J., Johnson, M. K., \& Mather, M. (2003). Source monitoring and suggestibility to misinformation: Adult age-related differences. Applied Cognitive Psychology, 17, 107119. doi:10.1002/acp.857 
Mitchell, K. J., Johnson, M. K., Raye, C. L., Mather, M., \& D'Esposito, M. (2000). Aging and reflective processes of working memory: Binding and test load deficits. Psychology and Aging, 15, 527-541. doi:10.1037/0882-7974.15.3.527

Mitchell, K. J., \& Zaragoza, M. S. (1996). Repeated exposure to suggestion and false memory: The role of contextual variability. Journal of Memory and Language, 35, 246-260. doi:10.1006/jmla.1996.0014

Multhaup, K. S., de Leonardis, D. M., \& Johnson, M. K. (1999). Source memory and eyewitness suggestibility in older adults. Journal of General Psychology, 126, 74-84. doi:10.1080/00221309909595352

Perfect, T. J., Wagstaff, G. F., Moore, D., Andrews, B., Cleveland, V., Newcombe, S., \& Brown, L. (2008). How can we help witnesses to remember more? It's an (eyes) open and shut case. Law and Human Behavior, 32, 314-324. doi:10.1007/s10979-007-9109-5

Penzien, P. 1985. The effects of hypnosis, contextual reinstatement, and task motivating instructions on memory recall. Unpublished Doctoral Dissertation, Ohio University.

Poole, D. A., \& Lindsay, D. (1995). Interviewing preschoolers: Effects of nonsuggestive techniques, parental coaching, and leading questions on reports of nonexperienced events. Journal of Experimental Child Psychology, 60, 129-154. doi:10.1006/jecp.1995.1035

Poole, D., \& Lindsay, D. (2001). Children's eyewitness reports after exposure to misinformation from parents. Journal of Experimental Psychology: Applied, 7, 27-50. doi:10.1037/1076898X.7.1.27

Poole, D., \& Lindsay, D. (2002). Reducing child witnesses' false reports of misinformation from 
parents. Journal of Experimental Child Psychology, 81, 117-140. doi:10.1006/jecp.2001.2648

Roebers, C. M., Moga, N., \& Schneider, W. (2001). Journal of Experimental Child Psychology, 78, 313-329. doi:10.1006/jecp. 2000.2577

Schacter, D. L., Koutstaal, W., Johnson, M. K., Gross, M. S., \& Angell, K. E. (1997). False recollection induced by photographs: A comparison of older and younger adults. Psychology and Aging, 12, 203-215. doi:10.1037/0882-7974.12.2.203

Seidler, K. M. \& Howie, P. M. (1999). Motivational factors in children’s reporting of events: The influence of age and expected reinforcement contingency. Journal of Applied Developmental Psychology, 20, 101-118. doi: 10.1016/S0193-3973(99)80006-9

Shapiro, P. N., \& Penrod, S. (1986). Meta-analysis of facial identification studies. Psychological Bulletin, 100(2), 139-156. doi:10.1037/0033-2909.100.2.139

Smith, S. M., \& Vela, E. (2001). Environmental context-dependent memory: A review and metaanalysis. Psychonomic Bulletin \& Review, 8(2), 203-220. doi:10.3758/BF03196157

Thierry, K. L., Lamb, M. E., Pipe, M., \& Spence, M. J. (2010). The flexibility of sourcemonitoring training: Reducing young children's source confusions. Applied Cognitive Psychology, 24(5), 626-644. doi:10.1002/acp.1574

Thierry, K. L., \& Spence, M. J. (2002). Source-monitoring training facilitates preschoolers' eyewitness memory performance. Developmental Psychology, 38(3), 428-437. doi:10.1037/0012-1649.38.3.428

Tulving, E., \& Thomson, D. M. (1973). Encoding specificity and retrieval processes in episodic memory. Psychological Review, 80(5), 352-373. doi:10.1037/h0020071

Wagstaff, G., Brunas-Wagstaff, J., Cole, J., \& Wheatcroft, J. (2004). New directions in forensic 
hypnosis: Facilitating memory with a focused meditation technique. Contemporary Hypnosis, 21, 14-27. doi:10.1002/ch.284

Wagstaff, G., Brunas-Wagstaff, J., Cole, J., Knapton, L., Winterbottom, J., Crean, V., \& Wheatcroft, J. (2004). Facilitating memory with hypnosis, focused meditation, and eye closure. International Journal of Clinical and Experimental Hypnosis, 52, 434-455. doi:10.1080/00207140490889062

Wagstaff, G., Cole, J., Wheatcroft, J., Marshall, M., \& Barsby, I. (2007). A componential approach to hypnotic memory facilitation: Focused meditation, context reinstatement and eye movements. Contemporary Hypnosis, 24, 97-108. doi:10.1002/ch.334

Wagstaff, G. F., \& Mercer, K. (1993). Does hypnosis facilitate memory for deep processed stimuli? Contemporary Hypnosis, 10(2), 59-66. Retrieved from EBSCOhost.

Winningham, R. G., Hyman, I. r., \& Dinnel, D. L. (2000). Flashbulb memories? The effects of when the initial memory report was obtained. Memory, 8(4), 209-216. doi:10.1080/096582100406775

Zaragoza, M. S., \& Lane, S. M. (1998). Processing resources and eyewitness suggestibility. Legal and Criminological Psychology, 3, 305-320. Retrieved from EBSCOhost.

Zaragoza, M. S., \& Mitchell, K. J. (1996). Repeated exposure to suggestion and the creation of false memories. Psychological Science, 7, 294-300. doi:10.1111/j.14679280.1996.tb00377.x

Zaragoza, M. S., Payment, K. E., Ackil, J. K., Drivdahl, S. B., \& Beck, M. (2001). Interviewing witnesses: Forced confabulation and confirmatory feedback increase false memories. Psychological Science, 12, 473-477. doi:10.1111/1467-9280.00388 


\section{Tables}

Table 1

Accuracy on Source Monitoring Test by Condition

\begin{tabular}{lccc}
\hline & \multicolumn{3}{c}{ Source Monitoring Test } \\
\cline { 2 - 4 } Condition & $n$ & $M$ & $S D$ \\
\hline & & & \\
Focused & 21 & 14.80 & 3.09 \\
Meditation & 19 & 14.26 & 2.64 \\
$\begin{array}{l}\text { Motivational } \\
\text { Instructions }\end{array}$ & & & \\
Control & 19 & 14.21 & 2.95 \\
\hline
\end{tabular}


Table 2

Accuracy on Each Type of Source Monitoring Question by Condition

\begin{tabular}{|c|c|c|c|c|c|c|c|c|}
\hline \multirow[b]{2}{*}{ Condition } & \multicolumn{2}{|c|}{ Questions Only } & \multicolumn{2}{|c|}{$\begin{array}{l}\text { Video and } \\
\text { Questions }\end{array}$} & \multicolumn{2}{|c|}{ Video Only } & \multicolumn{2}{|c|}{ New Information } \\
\hline & $\mathrm{M}$ & SD & $\mathrm{M}$ & SD & $\mathrm{M}$ & SD & $\mathrm{M}$ & SD \\
\hline $\begin{array}{l}\text { Focused } \\
\text { Meditation }\end{array}$ & 1.66 & 1.77 & 4.57 & 1.24 & 4.80 & 1.66 & 3.76 & .43 \\
\hline $\begin{array}{l}\text { Motivational } \\
\text { Instructions }\end{array}$ & 1.94 & 1.92 & 4.26 & 1.62 & 4.84 & 1.74 & 3.21 & .71 \\
\hline Control & 1.42 & 1.12 & 4.10 & 1.24 & 5.26 & 1.66 & 3.42 & .60 \\
\hline
\end{tabular}

Note: $N=59$. 
Table 3

Accurate and Inaccurate Recall on Free Recall Task by Condition

\begin{tabular}{lcccccc}
\hline & \multicolumn{3}{c}{ Accurate Recall } & \multicolumn{3}{c}{ Inaccurate Recall } \\
\cline { 2 - 7 } Condition & $n$ & $M$ & $S D$ & $n$ & $M$ & $S D$ \\
\hline & 21 & 22.04 & 4.89 & 21 & 3.04 & 2.03 \\
$\begin{array}{l}\text { Focused } \\
\text { Meditation }\end{array}$ & 18 & 17.94 & 8.10 & 19 & 2.94 & 3.18 \\
$\begin{array}{l}\text { Motivational } \\
\text { Instructions }\end{array}$ & 19 & 22.21 & 7.17 & 19 & 4.05 & 2.22 \\
Control & & & & & & \\
\end{tabular}


Table 4

Participants' Expectancies by Condition

Expectancy

Condition

$n$

M

$S D$

Focused

21

2.33

.96

Meditation

Motivational

19

2.94

.70

Instructions

Control

19

3.15

.50 